Research Note

Journal of Extension Education

Vol. 31 No. 4, 2019

DOI:https://doi.org/10.26725/JEE.2019.4.31.6411-6416

\title{
Use of Digital Tools for Horizontal Spread of Agricultural Technologies by Farmers of Kerala
}

\author{
Alan Jolly Sebastian ${ }^{1}$ and G. Jayalekshmi ${ }^{2}$
}

\begin{abstract}
In this digital era, integration of digital tools is common in every sector and agriculture is not an exception. The present study was conducted among the farmers of Kerala who were using various digital tools, during the year 2018-2019. The sample of the study consisted of 120 farmers from three zones of Kerala. Awareness and Preference of the respondents were studied in order to find out the horizontal spread. Based on the results obtained it was found that all farmers were aware about tools like television, mobile phone and social media. Most of the farmers had selected mobile phones as the most preferred tool. Farmers were found to use mobile phones mainly for 'crop protection' purposes and social media for 'marketing' purposes.
\end{abstract}

Keywords: Digital tools; Information and Communication Technology; Awareness; Preference; Farmers; Kerala.

Developing countries like India are having serious shortage of extension agents who play as intermediaries between farmers and researchers. This will adversely affect the overall development of agriculture because of the inefficiency to provide timely consultation and information. Digital tools can complement this gap between the farmers and extension personnel by giving timely information provided from the extension agents without physical presence. The agricultural sector of Kerala is unique mainly through the small land holdings and homestead farming, Farmers focus to get more revenue by diversifying their crops which points out to the need of variety of information. The efficient method to provide this information in a quick time is through the use of digtal tools.

The National Commission on Farmers had noted that knowledge deficits constrain agricultural productivity in India. It added that the use of Information and Communication Technologies (ICTs) for agricultural extension is one way of addressing the information needs of farmers. Utilizing such new applications and services on mobile phones help the extension personnel for accurate, speedy, and timely supply of information to the farmers in various

\footnotetext{
${ }^{1}$ PG Scholar, Department of Agricultural Extension, College of Agriculture, Vellayani, Thiruvananthapuram, Kerala695522 and ${ }^{2}$ Assistant Professor and Programme Coordinator, Krishi Vigyan Kendra, Kumarakom, Kottayam, Kerala- 686563.
}

Received : 19-08-2019; Accepted : 05-06-2020 
aspects related to agricultureandallied sciences (Kumari, 2016). In this scenario it is essential to study about the current status on the usage of digital tools by the farmers. The results obtained from the study will be useful to decide how to transfer the information effectively to reach the end users based on the popularity of various tools and also to modify the existing methods followed by the government and other institutes.

\section{METHODOLOGY}

The present study was conducted in three districts of Kerala representing the three zones of the state namely Kannur from the northern zone, Thrissur from the central zone and Thiruvananthapuram from the southern zone. From each district, 40 farmers who were already using some sort of digital tools was selected comprising of a total of 120 farmers through purposive random sampling. The idea of the study was to find out the extent of awareness of farmers on various digital tools with the preference towards each tool and also to find the usage of various digital tools by the farmers. Based on expert opinions 13 digital tools were identified which were as most common in the present situation. Usage of digital tools by farmers was mainly focused on crop production, crop protection and marketing purposes.

Summing up of the scores was done for better interpretation of the results obtained. Awareness was classified as aware and unaware, while preference was measured in a three point continuum as always, sometimes and never. Farmers were then classified based on the data obtained to find the extent of awareness and preference for various digital tools. Categorization of the respondents based on the usage of tools for crop production, crop protection and marketing was also done.

\section{FINDINGS AND DISCUSSION}

\section{Awareness of farmers about digital tools}

It was observed that all the respondents were aware about tools like television, mobile phone and social media which was also the popular digital tool at the time of investigation. The results were found to be in agreement with findings of Kumar (2018) and Khidir et al. (2019). High level of awareness was also found for internet (96.67\%), email (85\%), search engines (80.83\%) and e newspapers $(75.83 \%)$. While majority of the farmers were unaware about tools like agricultural expert systems (92.50\%), information kiosk (84.17\%) and agricultural websites (72.50\%).The unawareness for these tools may be due to lack of popularity and lack of accessibility of these tools. Farmers were found to be bound to simple and easy technologies. About half of the respondents were aware about tools like computer (57.50\%), video conferencing (50 \%) and mobile agricultural applications (59.16\%). The results mainly shows that farmers were mostly aware of the tools that were most commonly used by everyone. These tools were having versatile uses. The tools which focused exclusively for the disbursement of agricultural information like agricultural websites, expert systems and information kisoks were less aware for the respondents and is usually used only by experts. These tools should be 
Use of Digital Tools for Horizontal Spread of Agricultural Technologies by Farmers of Kerala

Table 1.

Distribution of Farmers based on Awareness about Digital Tools

$(n=120)$

\begin{tabular}{|c|c|c|c|c|c|}
\hline \multirow{3}{*}{$\begin{array}{l}\text { Sl. } \\
\text { No. }\end{array}$} & \multirow{3}{*}{ Digital Tools } & \multicolumn{4}{|c|}{ Awareness } \\
\hline & & \multicolumn{2}{|c|}{ Aware } & \multicolumn{2}{|c|}{ Unaware } \\
\hline & & Frequency & Percentage & Frequency & Percentage \\
\hline 1. & Television & 120 & 100 & 0 & 0 \\
\hline 2. & Mobile phone & 120 & 100 & 0 & 0 \\
\hline 3. & Computer & 69 & 57.50 & 51 & 42.50 \\
\hline 4. & Internet & 116 & 96.67 & 4 & 3.33 \\
\hline 5. & Social media & 120 & 100 & 0 & 0 \\
\hline 6. & Information kisok & 19 & 15.83 & 101 & 84.17 \\
\hline 7. & e Mail & 102 & 85 & 18 & 15 \\
\hline 8. & Search engines & 97 & 80.83 & 23 & 19.17 \\
\hline 9. & Agricultural websites & 33 & 27.50 & 87 & 72.50 \\
\hline 10. & Video conferencing & 60 & 50 & 60 & 50 \\
\hline 11. & Agricultural expert systems & 9 & 7.50 & 111 & 92.50 \\
\hline 12. & $\begin{array}{l}\text { Mobile agricultural } \\
\text { applications }\end{array}$ & 71 & 59.16 & 49 & 40.83 \\
\hline 13 & e Newspaper & 91 & 75.83 & 29 & 24.17 \\
\hline
\end{tabular}

pushed forward in a compatible way since these tools can primarily focus on providing agricultural information of the farmers. Table 1 shows distribution of the farmers based on the awareness for digital tools.

Preference for various digital tools by farmers

The preference for various digital tools by farmers are given in Table 2 . It was identified that mobile phone (88.33 \%) was the most preferred tool by the farmers followed by social media (64.17\%) and television (50.83 $\%)$. In case of least preferred tools agricultural expert systems (98.33\%) and information kiosks (95.83 \%) were identified. The results were having similarity with the findings of Kumar (2018). Mobile phones and social media were mostly preferred by the farmers which may be due to the versatility and easiness to use, portable nature and relativity affordable. 
Table 2.

Distribution of Farmers based on Preference for various Digital Tools

$(n=120)$

\begin{tabular}{|c|l|c|c|c|c|c|c|}
\hline \multirow{2}{*}{$\begin{array}{c}\text { Sl. } \\
\text { No. }\end{array}$} & \multirow{2}{*}{ Digital Tool } & \multicolumn{2}{|c|}{ Always } & \multicolumn{2}{c|}{ Sometimes } & \multicolumn{2}{c|}{ Never } \\
\cline { 2 - 8 } & & Freq. & $\%$ & Freq. & $\%$ & Freq. & $\%$ \\
\hline 1. & Television & 61 & 50.83 & 54 & 45 & 5 & 4.17 \\
\hline 2. & Mobile phone & 106 & 88.33 & 13 & 10.83 & 1 & 0.83 \\
\hline 3. & Computer & 9 & 7.5 & 43 & 35.83 & 68 & 56.67 \\
\hline 4. & Internet & 50 & 41.67 & 65 & 54.17 & 5 & 4.17 \\
\hline 5. & Social Media & 77 & 64.17 & 42 & 35 & 1 & 0.83 \\
\hline 6. & Information Kiosk & 0 & 0 & 5 & 4.17 & 115 & 95.83 \\
\hline 7. & e Mail & 5 & 4.17 & 59 & 49.17 & 56 & 46.67 \\
\hline 8. & Search Engines & 5 & 4.17 & 71 & 59.17 & 44 & 36.67 \\
\hline 9. & Agricultural websites & 0 & 0 & 27 & 22.5 & 93 & 77.5 \\
\hline 10. & Video Conferencing & 0 & 0 & 27 & 22.5 & 93 & 77.5 \\
\hline 11. & $\begin{array}{l}\text { Agricultural expert } \\
\text { systems }\end{array}$ & 0 & 0 & 2 & 1.67 & 118 & 98.33 \\
\hline 12. & Mobile agricultural & 7 & 5.83 & 54 & 45 & 59 & 49.17 \\
\hline 13. & applications & & & & & & \\
\hline
\end{tabular}

(Jain et al., 2015). Mobile phones and social media can also provide a personal feedback for the queries of farmers by experts and fellow farmers. On the other hand Information Kiosks and Expert Systems might have been too complex for the farmers. Information Kiosks were only used to provide more of agricultural information and less of market information for the farmers. It is also essential to simplify these tools through developing in local languages which can improve the usability of these tools.
Categorization of the digital tools based on usage

Selected digital tools were categorized into three categories. Crop production, which includes site preparation, selection of varieties, cultivation practices and harvesting of crops. Crop protection, including pest and disease control. The third category was 'Marketing'. It was revealed that television, mobile phones, computer and social media were the main tools used for these purposes. Categorization of the selected tools from the 
Use of Digital Tools for Horizontal Spread of Agricultural Technologies by Farmers of Kerala

Table 3.

Categorization of Digital Tools based on Usage

\begin{tabular}{|c|l|c|c|c|c|c|c|}
\hline \multirow{2}{*}{ SI. No. } & \multirow{2}{*}{ Digital Tools } & \multicolumn{2}{|c|}{ Crop Production } & \multicolumn{2}{c|}{ Crop Protection } & \multicolumn{2}{|c|}{ Marketing } \\
\cline { 3 - 8 } & & Freq. & $\%$ & Freq. & $\%$ & Freq. & $\%$ \\
\hline 1. & Television & 35 & 29.17 & 34 & 28.33 & 0 & 0 \\
\hline 2. & Mobile phone & 47 & 39.17 & 70 & 58.33 & 84 & 70 \\
\hline 3. & Computer & 0 & 0 & 27 & 22.5 & 3 & 2.5 \\
\hline 4. & Social media & 36 & 30 & 69 & 57.5 & 99 & 82.5 \\
\hline
\end{tabular}

mentioned aspects were done as given in Table 3. Mobile phones were the tools used by most of the farmers for crop production (39.17\%) as well as crop protection (58.33 $\%)$ purposes. Mobile phones provided instant information about cultivation practices and plant protection measures through phone calls and SMS services. Majority (82.50\%) of the farmers used social media for marketing the produce. Marketing was mainly done through Whatsapp and Facebook groups. Farmers preferred Whatsapp and Facebook than any other e-commercial sites which is similar to the findings of Pichapillai (2020). Social media can help farmers to connect the buyers in nearby area and also helped to fetch a better price than the market value. Farmers' groups in social media can improve the bargaining power of the farmers and fix the price according to the demand.

It was observed that most of the farmers were having higher level of awareness for tools like mobile phones, television and social media. Most of the farmers had preferred mobile phone as a general tool for frequent use. Mobile phones were mainly used for gathering information for crop production and protection purposes whereas 'social media' was preferred mainly for marketing. The study indicates that the present usage of digital tools by farmers were restricted only for a few common tools due to its easiness to use and versatility. Creating awareness among the farmers, use of local languages, updating information on regular basis and expanding the services should be done. Creating an all in one portal by collecting all the scattered information on agriculture including plant production, plant protection, marketing and expert services can be a better solution to improve the usage of ICT tools.

\section{REFERENCES}

Jain, L., Kumar, H. \& Singla, R.K., (2015). Assessing mobile technology usage for knowledge dissemination among farmers in Punjab. Information Technology for Development, 21(4), 668676. 
Khidir, A. A., Oladele, O. I. \& Yusuf, O. J. (2019). Use of Mobile Phone Applications by Farmers in NorthWest Nigeria. Journal of Agricultural Extension, 23(3), p.182-195.

Kumar, A. (2018). Role of social media in dissemination of agricultural innovations in Haryana. Unpublished MSc (Ag.) thesis. Chaudhary Charan Singh Haryana Agricultural University. 69p.
Kumari, N. S. (2016). Tools and services for m-extension: problems and prospects. Unpublished Msc (Ag) thesis. Kerala Agricultural University, Thrissur, Kerala, p154.

Pichapillai, S. (2020). An economic analysis of social media and agriculture marketing in Tamil Nadu. Studies in Indian Place Names, 40(12), 671-677. 